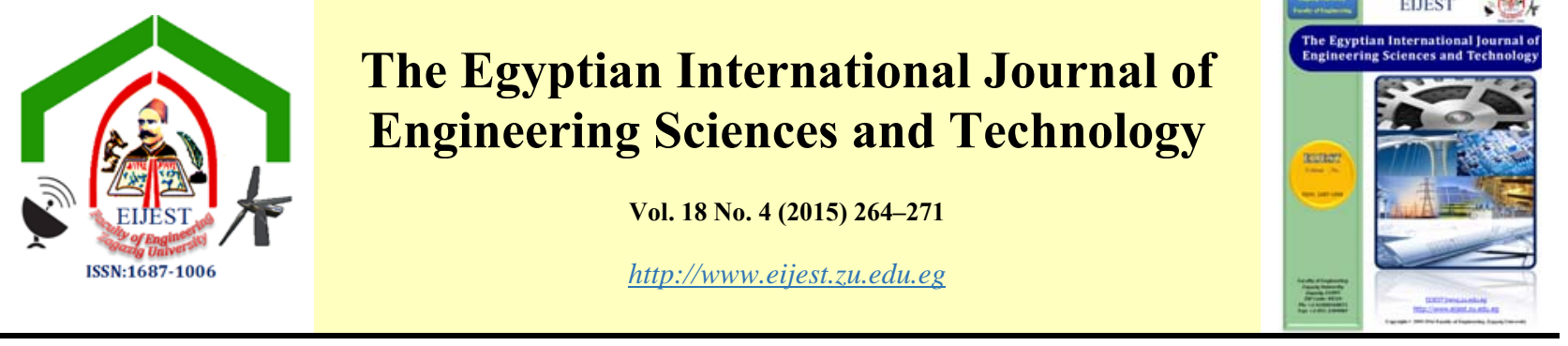

\title{
Thermal Performance of Finned Heat Sinks - State of The Art
}

\author{
Saeed A.A. Ibrahim, Mohammad R. Shaalan, Mohammad A. Saleh \\ Faculty of Engineering ,Zagazig University, Egypt \\ Mech. Power Engineering Department, Zagazig University., Egypt
}

\begin{tabular}{|c|c|}
\hline A R T I CLE I N FO & A B S T RACT \\
\hline $\begin{array}{l}\text { Article history: } \\
\text { Received } 1^{\text {st }} \text { Sept. } 2015 \\
\text { Received in revised form: } \\
\text { Accepted } 1^{\text {st }} \text { October } 2015 \\
\text { Available online: }\end{array}$ & $\begin{array}{l}\text { There has been deep interest by research workers in the thermal characteristics of } \\
\text { heat sinks as cooling devices in certain engineering systems (e.g. computer } \\
\text { microprocessors and motherboards). The main emphasis has been on how to } \\
\text { enhance the heat transfer rate from such cooling devices. Finned surfaces were one } \\
\text { obvious solution in this case. Vapor chamber heat sinks may also be another } \\
\text { solution. }\end{array}$ \\
\hline $\begin{array}{l}\text { Keywords: } \\
\text { heat sink } \\
\text { finned surface } \\
\text { heat transfer } \\
\text { cooling process } \\
\text { vapor chamber }\end{array}$ & $\begin{array}{l}\text { This paper gives an over view of up-to-date published research in the area of flat } \\
\text { plate type heat sinks provided with fins. Some } 40 \text { articles were reviewed and } \\
\text { examined, covering various aspects of the subject. Each article was critically } \\
\text { evaluated. Aspects requiring further work and deeper insight were spotted, drawing } \\
\text { attention to their importance. Suggestions for possible means thought to augment } \\
\text { the heat transfer rate of heat sinks were postulated. }\end{array}$ \\
\hline
\end{tabular}

\section{Introduction}

Heat sinks have long been known and used as effective tools for the extraction of undesirable heat generated in some engineering systems. Heat pipes are among such tools. In applications such as the cooling of computer hardware components (microprocessors, motherboards, power supplies, etc). Heat sinks with flat or near flat surfaces are preferable. These surfaces need to be provided with fins for enhancing the heat transfer surface, hence increasing the amount of heat that can be transferred away from the system component. Heat sinks may be mounted on what is called " vapor chamber " in an attempt to improve its performance. Fig (1) shows a diagrammatic of a typical finned- type heat sink and Fig.(2) shows the general construction of a vapor chamber. However, published work on heat sinks mounted on a vapor chamber is relatively scanty. Performance of the vapor chambers themselves has been investigated by a number of researchers.

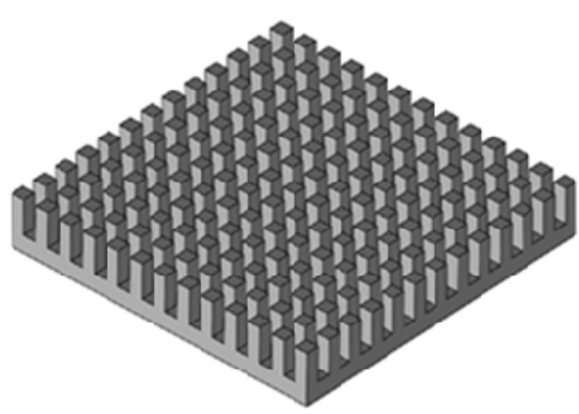

Fig. (1) : A typical finned heat sink 


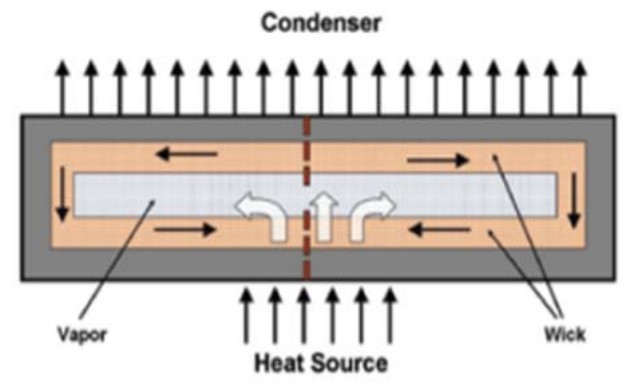

Fig(2) : Vapor chamber build

Massive work on the improvement of heat sink effectiveness for cooling certain system components has hitherto been carried out and published. Concentration has been mainly on finned type of heat sinks of the flat surface category.

In the following section, the most pertinent articles published on the subject will be summarized, attempting to throw some light on the principal aspects considered in each article. Next, an overall evaluation of the current status will be given.

\section{Synopses of Published Work}

\subsection{Vapor chamber/heat sinks}

Wang et Vafai ${ }^{41}(2000)$ investigated experimentally the thermal performance of a vapor chamber. They found that the temperature distribution on the surface of the wall in the condenser section was uniform. The porous wick in the evaporator section provided most of the thermal resistance and a higher temperature drop than the other layers in the chamber.

Kalahasti et Joshi ${ }^{20}(2002)$ found that the primary limitation on heat transfer using a vapor chamber was the capillary limitation of the wick structure. The wall thermal conductivity strongly influenced the performance of the chamber.

Sauciuc et al ${ }^{35}(2002)$ proposed models to predict the spreading resistance of vapor chambers. They identified a threshold envelope where a solid metal may have a lower spreading resistance than a vapor chamber.

Go ${ }^{13}(2005)$ presented experimental results that elucidated the effects of heating power and tilt angle on the thermal resistance of a vapor chamber, and found that the vapor chamber works effectively under high-power conditions.

Tan et al ${ }^{37}(2005)$ presented an analytical method for predicting the velocity and pressure distributions in a vapor chamber. They discussed the locations of the heat sources that optimize performance.

Koito et al ${ }^{23}(2005)$ identified large temperature drops in the liquid-wick region and the solid wall region of a vapor chamber close to the heat source. Therefore, reducing the thermal resistance in these regions was important for further improvement of the thermal performance of the chamber.

Koito et al ${ }^{24}(2006)$ carried out a numerical analysis on a flat-plate type heat pipe (called "vapor chamber"). The mathematical model formulated for the vapor chamber was a two-phase closed diskshaped chamber and was placed between a small heat source and a large heat sink. Wick sheets and a wick column were provided inside the vapor chamber to circulate the working fluid. By solving the equations of continuity, momentum and energy numerically, the velocity, pressure and temperature distributions inside the vapor chamber were obtained. From the numerical results, the capillary pressure head necessary to circulate the working fluid was estimated and the temperature drop inside the vapor chamber was determined. These numerical results were useful for the design and improvement of the vapor chamber.

Koito et al ${ }^{25}(2006)$ studied experimentally and numerically the effect of the size of the heat source on the heat transfer of a vapor chamber. The total thermal resistance of the vapor chamber was almost equal to that of the evaporator section, because the thermal resistance of the condenser section was very low. The thermal resistance increased as the size of the heat source decreased.

Boukhanouf et al ${ }^{4}(2006)$, determined the thermal performance of a vapor chamber using an infra-red thermal imaging camera. The thermal spreading resistance of the vapor chamber was lower than that of the solid copper and the defective vapor chamber.

Chen et al ${ }^{6}(2007)$ indicated that the thermal 
resistance of the metal plate was independent of input power, but the thermal resistance of the vapor chamber clearly decreased as the power increased. The surface temperature distribution of the vapor

chamber was more uniform than the metal plate and less sensitive to the heat source size and the input power.

Hsieh et al ${ }^{16}(2007)$ presented a three-dimensional analytical solution using product solutions via the separation of variables for spreading thermal resistances of centrally- positioned heat sources of a vapor chamber heat sink with and without a partition for electronic cooling is presented. A parametric study including partition thickness and height was performed and the effect of the relevant parameters on the heat transfer performance in terms of the base spreading resistance was examined.

Hsieh et al ${ }^{17}(2008)$ performed experiments to examine the spreading thermal resistance of centrally- positioned heat sources and the thermal performance of a water- charged, gravity- assisted flat vapor chamber to be used for electronic cooling. Parametric studies including different heat fluxes and operating temperatures were conducted, and the effect of the relevant parameters on the cooling performance in terms of the spreading resistance was presented and discussed. The used vapor chamber heat spreader showed a heat removal capacity of 220 $\mathrm{W} / \mathrm{cm}^{2}$ with a thermal spreading resistance of 0.2 ${ }^{\circ} \mathrm{C} / \mathrm{W}$.

\subsection{Heat Pipe Operation Modeling}

Ooijen et Hoogendoorn ${ }^{31}(1979)$ presented a steady-state numerical analysis of the vapor core in a horizontal flat heat pipe.

Tournier et El-Genk ${ }^{38}(1993)$ developed a twodimensional model for the transient analysis of heat pipes. The analysis determined the radius of curvature of the liquid meniscus formed in the wick pores.

Zhu et Vafai ${ }^{46}$ (1998) studied the startup operating characteristics of asymmetrical flat-plate and disk shaped heat pipes using analytical models.
Garimella et Sobhan ${ }^{11}(2001)$ reviewed the state of the art in the understanding and analysis of a large variety of heat pipes, and also identified the respective limitations. Modeling of heat pipes is complicated by the various mechanisms of heat, mass and momentum transport prevalent in the device, viz., the capillarity of the porous medium, evaporation/condensation in the wick structure, and conduction in the solid wall, among others. Models with approximate coupling between the various transport mechanisms have been developed and have led to fair predictions of heat pipe performance.

Vadakkan et al ${ }^{39}(2003)$ developed a stable numerical procedure to analyze the transient performance of flat heat pipes for large input heat fluxes and high wick conductivity. Computation of flow and heat transfer in a heat pipe is complicated by the strong coupling among the velocity, pressure and temperature fields with phase change at the interface between the vapor and wick. The numerical scheme was applied to a flat two-dimensional heat pipe and was shown to perform well. Parametric studies were performed by varying the vapor core thickness of the heat pipe and the heat input at the evaporator. The model predictions were validated by comparing the heat pipe wall temperatures against experimental values.

Kim et al ${ }^{22}(2003)$ proposed a one-dimensional mathematical model for a miniature heat pipe with a grooved wick structure to predict its thermal performance characteristics.

Hanlon et $\mathrm{Ma}{ }^{15}(2003)$ presented a twodimensional model to predict the overall heat transfer capability of a sintered wick structure. They concluded that thin-film evaporation from the top surface of the sintered wick plays a major role in enhancing heat transfer. Failure to establish an adequate thin-film evaporation condition, such as for non-wetting liquids, on the top surface of the wicks was shown to result in a significant decrease in the rate of evaporation.

Vadakkan et al ${ }^{40}(2004)$ developed a threedimensional numerical model to study the 
performance of flat heat pipes with multiple discrete heat sources. The effects of heat source strength and separation on steady as well as transient performance were studied. The wick-vapor interface was assumed to be flat and local curvature effects were not considered.

Ghajar et al ${ }^{12}(2005)$ developed a hybrid CFDmathematical model to predict the performance of a micro loop heat pipe (MLHP) as a function of input heat rate. Two-phase pressure drop in the condenser was calculated by several two- phase correlations and the results were compared. Capillary tube correlations were used for pressure drop calculations

in fluid lines. Effects of working fluid and change in geometry were studied.

Koito et al ${ }^{26}(2006)$ developed a numerical model to solve the flow and energy equations in vapor chambers and estimated the capillary pressure head necessary to circulate the working fluid inside the vapor chamber.

Mwaba et al ${ }^{30}(2006)$ studied the influence of wick characteristics on heat pipe performance using numerical methods. They considered screen-mesh and sintered-copper wicks as the porous medium in heat pipes and pointed out that a heat pipe with a composite wick structure gives the best performance.

Rice et Faghri ${ }^{33}$ (2007) performed a complete numerical analysis of heat pipes with no empirical correlations while including the flow in a wick. The numerical model was validated from experimental and numerical work. Single and multiple heat sources were used as well as constant, convective and radiative heat sinks. The numerical model did not fix the internal pressure references by a point, but allowed to rise and fall based on the physics of the problem. Also, the capillary pressure needed in the wick to drive the flow was obtained for various heating configurations and powers. These capillary pressures, in conjunction with an analysis that predicted the maximum capillary pressure for a given heating load was used to determine the dry-out limitations of a heat pipe.

Carbajal et al ${ }^{5}(2007)$ used a quasi-3D numerical analysis to obtain the temperature distribution on the back side of a flat heat pipe. They demonstrated that the flat heat pipe led to a more uniform temperature distribution on the condenser side compared to a solid heat spreader.

Xiao et Faghri ${ }^{44}(2008)$ developed a threedimensional heat pipe model which accounted for heat conduction in the wall and fluid flow in the vapor core and porous wicks.

Do et al ${ }^{10}(2008)$ developed a mathematical model for predicting the thermal performance of a flat micro heat pipe with a rectangular-grooved wick structure. They considered the effects of liquid-vapor interfacial shear stress and contact angle on device performance. Axial variations of wall temperature and the evaporation and condensation rates were also included in the model.

Chen et al $^{7}(2008)$ conducted a theoretical model of fluid flow and heat transfer in a heat pipe with axial " $\Omega$ "-shaped grooves to study the maximum heat transport capability of these types of heat pipes. The effect of vapor core and wick structure on the fluid flow characteristics and the effect of the heat load on the capillary radius at the evaporator end cap, as well as the effect of the wick structure on the heat transfer performance were all analyzed numerically and discussed. The axial distribution of the capillary radius, fluid pressure and mean velocity were obtained. In addition, the calculated maximum heat transport capability of the heat pipe at different working temperatures was compared with that obtained from a traditional capillary pressure balance model, in which the interfacial shear stress is neglected.

Singh et al ${ }^{36}(2009)$ studied the effect of wick properties on the heat transfer characteristics of miniature loop heat pipes. Capillary structures with smaller pore size, high porosity, and high permeability showed better heat transfer characteristics in their experiments. It was experimentally observed that copper wicks are able to provide superior thermal performance than nickel wicks, particularly for low to moderate heat loads due to their low heat conducting resistance. With mono porous copper wick, maximum evaporator heat transfer coefficient of $26,270 \mathrm{~W} / \mathrm{m}^{2} . \mathrm{K}$ and evaporator thermal resistance of $0.06-0.10^{\circ} \mathrm{C}$ were achieved. For mono porous nickel wick, the corresponding values were $20,700 \mathrm{~W} / \mathrm{m} 2 . \mathrm{K}$ and $0.08-0.21{ }^{\circ} \mathrm{C}$ for evaporator thermal resistance. Capillary structure with smaller pore size, high 
porosity, and high permeability showed better heat transfer characteristics due to sufficient capillary pumping capability. In addition, bi-porous copper wick structure showed a much higher heat transfer coefficient of $83,787 \mathrm{~W} / \mathrm{m} 2 . \mathrm{K}$ than a monoporous copper wick due to improved evaporative heat transfer at wick wall interface and separated liquid and vapor flow pores.

Weibel et al ${ }^{43}(2010)$, showed that nucleate boiling occurs in the wick structure of a heat pipe, leading to a reduction in the wick thermal resistance. Also, the existing models in the literature do not account for the coupling of transport processes at the wick- and device-levels. With device miniaturization and increasing power density, it is important to develop a robust heat pipe model which is reliable for the prediction of device performance at high heat inputs and small length scales.

\subsection{Heat and Mass Transport in Wicked Structures}

Avoiding dry out and overheating in heat pipes is a critical consideration and has been the focus of much research over the past few years. Many studies have proposed methods to develop permeability measurement techniques, characterize wick porosity, and quantify the overall performance of heat pipes. Most have focused on determining dry out heat fluxes and the limits of operation for a given wicking mechanism.

Potash et Wayner ${ }^{32}(1972)$ modeled and analyzed the transport processes occurring in an evaporating 2D meniscus and adsorbed thin film formed on a superheated flat glass plate $\left(0.272^{\circ} \mathrm{C}\right.$ superheat) immersed in a pool of saturated carbon tetrachloride. Fluid flow resulted from a change in the external meniscus profile. The pressure gradient of the fluid flow included the effect of disjoining pressure. The resulting extended meniscus profile, heat flux profile, and pressure derivative profile were calculated. The presence of an adsorbed superheated film resulted in a smooth transition between the evaporating and nonevaporating portions of the extended meniscus.

Abhat et Seban ${ }^{1}(1974)$ performed experiments to study boiling and evaporation from heat pipe wicks with water and acetone. They indicated that the evaporative performance of a wick can be limited as much by a failure of capillary suction as due to fluid friction in the wick.

$\mathrm{Xu}$ et Carey ${ }^{45}(1990)$ presented an analytical model that can be used to predict the heat-transfer characteristics of film evaporation on a microgroove surface. The model assumed that the liquid flow along a ' $\mathrm{V}$ ' shaped groove channel was driven primarily by the capillary pressure difference due to the receding of the meniscus toward the apex of the groove, and the flow up the groove side wall was driven by the disjoining pressure difference. It also assumed that conduction across the thin liquid film was the dominant heat transfer mode. The results of a limited experimental study of the heat transfer during vaporization of a liquid coolant on a microgroove surface were also reported. The results suggested that disjoining pressure differences may play a central role in evaporation processes in microgroove channels.

Bauer ${ }^{3}(1993)$ developed general analytical approach to the thermal conductivity of porous media leading to theoretically sound expressions having a wide range of applicability and easily fitted to available empirical data. Specifically, practical expressions were derived for pore distributions of any concentration, randomly oriented pores of arbitrary shape, pores of any conductivity, radiant heat transfer within pores, and fibrous media. Most results transfer freely to electrical conductivity or any other general area where Laplace's equation applies. Fundamental limitations of the approach restricted its use to random pore distributions and heat transfer through the continuous medium by conduction.

Abo El-Nasr et El-Haggar ${ }^{2}(1996)$ designed and manufactured several heat pipes to study the effect of the working fluids, container materials, and the wick structures on the heat transfer mechanism. Also, the effect of the number of wick layers on the effective thermal conductivity and the heat transfer characteristics of the heat pipes were investigated. It was found that the flow behavior of the working fluid depended on the wicking structures and the number of wick layers. The heat transfer characteristics and the effective thermal conductivity were related 
directly to the flow behavior. Increasing the number of wick layers (up to 16 layers) increased the heat flux with smaller temperature differences. The flattening phenomena of the thermal resistance were observed after 16 wicks layers due to the entrainment limit.

Ma et Peterson ${ }^{27}$ (1997) developed a mathematical model for the evaporating heat transfer coefficient and temperature variation along the axial direction of a grooved plate. The model included the effects of the capillary-induced in the grooves caused by the surface tension, the two-dimensional heat conduction occurring in the wall and liquid film, and the evaporation of the thin him caused by the disjoining pressure and surface tension in the thin film region. The results obtained from this model indicated that if a constant heat flux boundary condition was applied, the heat transfer coefficient would decrease and the wall temperature would increase along the axial direction. In addition, the apparent contact angle increased with increasing superheat, hence, the heat transfer rate through the micro region also increased in the axial direction. Finally, it was demonstrated that the contribution of the surface tension variation caused by temperature increase in the micro region could be neglected.

Gupta et Upadhya ${ }^{14}(1999)$ reported maximum heat transfer rates for wrapped wire screen, square axial grooves, and sintered metal powder wicks. They found sintered metal powder wicks to be the most effective for heat transfer.

Morris ${ }^{28}(2001)$ developed a theoretical model to predict apparent contact angles for evaporating liquids.

Morris ${ }^{29}(2003)$ provided a relationship between heat flow, apparent contact angle, interface curvature, superheat and material properties for a perfectly wetting system; a conduction model with a fixed liquid-vapor interface was considered for estimating heat flow across the interface for small capillary number, flows with thermos-capillary and bulk flow effects being ignored.

Khrustalev et Faghri ${ }^{21}(1996)$ developed a mathematical model of the evaporating liquid-vapor meniscus in a capillary slot. They concluded that fluid flow could increase the heat transfer by up to $30 \%$. However, only a $3-5 \%$ increase was reported for superheats below $5 \mathrm{~K}$.

Iverson et al. ${ }^{19}(2007)$ quantified wick performance including evaporation rates, for sintered copper powder wicks under conditions of operation in heat pipes. They compared the performance of four different sintered wicks of varying porosity.

Dhavaleswarapu et al ${ }^{9}(2007)$ visualized flow patterns near an evaporating meniscus using $\mu \mathrm{PIV}$ techniques and compared the influence of buoyancy and thermos-capillarity on the overall flow structure. This study led to a better understanding of an evaporating liquid meniscus and was useful in providing guidelines for the design of efficient microstructures for passive cooling devices.

Davis et Garimella ${ }^{8}(2008)$ measured the evaporative thermal resistance across thin layers of sintered copper wicks of varying porosity experimentally under saturated conditions.

Wang et al ${ }^{42}(2008)$ modeled Transport from a volatile meniscus inside an open micro-tube.

Sait et Ma ${ }^{34}(2009)$, constructed a unique experimental system to investigate the effect of heat flux on the film thickness in the evaporating thin-film region. The film thickness near the interline region was measured using a one-spot thin-film analyzer F20. Temperatures at the liquid-vapor interface near the interline region were measured using the micron infra-red camera. Experimental results showed that as the input power increased the film thickness near the interline region decreased, which was in agreement with the theoretical prediction.

Hung-Yi et al ${ }^{18}(2010)$ studied experimentally the thermal performance of plate-fin vapor chamber heat sinks using infra-red thermography. They studied the effects of the width, height and number of fins and of the Reynolds number on the thermal performance. They concluded that generated heat was transferred more uniformly to the base plate by a vapor chamber heat sink than by a similar aluminum heat sink. Therefore, the maximum temperature was effectively reduced. The overall thermal resistance of the vapor chamber heat sink declined as the Reynolds number increased, but the strength of the effect falls. The effect of fin dimensions on the thermal performance 
was stronger at a lower Reynolds number. At a low Reynolds number, a suitable number of fins was to be chosen to ensure favorable thermal performance of the vapor chamber heat sink. However, at a high Reynolds number, the thermal performance improved as the number of fins increased.

\subsection{Comments and Necessity of Further Work}

A review of the pertinent literature indicates that the vapor chamber can spread heat rapidly. The heat sink design can be adapted to improve electronic cooling. Most related works have emphasized the heat transfer characteristics of vapor chambers. However, in practice, a vapor chamber is commonly combined with heat sinks or fins to increase the area of heat transfer and improve cooling. Further work should investigate the performance of a vapor chamber attached to the base of various types of heat sinks. However, the case of heat sink with a pinfinned heat sink has not been considered well and this should be also looked into in addition to the effect of Reynolds number, fin height, with and without vapor chamber on the performance of various types of heat sinks.

\section{Evaluation of Current Status}

It appears from the above review that there is still much room for research in the area of heat sinks. Several aspects need be covered with care. For example, the effect of fin heights geometry and arrangement requires further investigation. Also, work on use of a vapor chamber between the heat source and the heat sink is rather scanty or may be nonexistent and deserves consideration. Extensive work is waiting to be done here. The authors are currently working on the problem and the results are planned to be published in a subsequent paper, hopefully soon.

\section{Proposal for Needed Investigations}

The following aspects of the problem heat sinks as cooling tools in engineering systems should be specifically examined both computationally and experimentally:

(i) A heat sink with pin-type fins of various heights and under various flow conditions. (ii) A heat sink with plate-type fins of various heights and under various flow conditions.

(iii) Each of the above two cases when a vapor chamber mounted between the sink and the heat source (load).

(iv) The effect of the vapor chamber fluid and its internal geometry on the thermos-fluid characteristics of a given heat sink.

\section{Conclusions}

(i) Heat sinks have been considered by numerous investigators so far.

(ii) The effect of various parameters still need more work.

(iii) Adding vapor chambers to the problem is thought worthy.

\section{References}

[1] Abhat, A., and Seban, R. A., 1974, Boiling and Evaporation from Heat Pipe Wicks with Water and Acetone, Journal of Heat Transfer 96 (3) (1974) 331-337.

[2] Abo El-Nasr, A., and El-Haggar, S. M., 1996, Effective Thermal Conductivity of Heat Pipes, Heat and Mass Transfer 32 (1-2) (1996) 97-101.

[3] Bauer, T. H., 1993, General Analytical Approach toward the Thermal Conductivity of Porous Media, International Journal of Heat and Mass Transfer 36 (17) (1993) 4181-4191.

[4] Boukhanouf, R., Haddad, A., North, M.T., and Buffone, C., Experimental investigation of a flat plate heat pipe performance using IR thermal imaging camera, Appl. Therm. Eng. 26 (2006) 2148-2156.

[5] Carbajal, G., Sobhan, C. B., Peterson, G. P., Queheillalt, D. T., and Wadley, H. N. G., A Quasi-3D Analysis of the Thermal Performance of a Flat Heat Pipe, International Journal of Heat and Mass Transfer 50 (2007) 4286-4296.

[6] Chen, Y.S., Chien, K.H., Wang, C.C., Hung, T.C., Ferng, Y.M., and Pei, B.S., Investigations of the thermal spreading effects of rectangular conduction plates and vapor chamber, J. Electron. Pack. 129 (2007) 348-355.

[7] Chen, Y., Zhang, C., Shi, M. Wu, J., and Peterson, G. P., Study on Flow and Heat Transfer Characteristics of Heat Pipe with Axial Omega-shaped Microgrooves, International Journal of Heat and Mass Transfer 52 (3-4) (2008) 636-643.

[8] Davis, T. W., and Garimella, S. V., Thermal Resistance Measurement across a Wick Structure using a Novel Thermosyphon Test Chamber, Experimental Heat Transfer 21 (2008) 143-154

[9] Dhavaleswarapu, H. K., Chamarthy, P., Garimella, S. V., and Murthy, J. Y., Experimental Investigation of Steady Buoyant-thermocapillary Convection near an Evaporating Meniscus, Physics of Fluids 19 (2007) 082103 (1-11).

[10] Do, K. H., Kim, S. J. and Suresh V. Garimella, A Mathematical Model for Analyzing the Thermal Characteristics of a Flat Micro Heat Pipe with a Grooved Wick, International Journal of Heat and Mass Transfer 51(19-20) (2008) 4637- 4650. 
[11] Garimella, S. V., and Sobhan, C. B., Recent Advances in the Modeling and Applications of Nonconventional Heat Pipes, Advances in Heat Transfer 35 (2001) 249-308.

[12] Ghajar, M., Darabi, J., and Crews Jr, N., A Hybrid CFDmathematical Model for Simulation of a MEMS Loop Heat Pipe for Electronics Cooling Applications, Journal of Micromechanics and Microengineering 15 (2005) 313-321.

[13] Go, J.S., Quantitative thermal performance evaluation of a cost-effective vapor chamber heat sink containing a metaletched microwick structure for advanced microprocessor cooling, Sens. Actuators A 121 (2005) 549-556.

[14] Gupta, A., and Upadhya, G., Optimization of Heat Pipe Wick Structures for Low Wattage Electronics Cooling Applications, Advances in Electronic Packaging 1999, Pacific RIM/ASME International Intersociety Electronics Photonic Packaging Conference, American Society of Mechanical Engineers, New York 26 (1999) 2129-2137.

[15] Hanlon, M. A., and Ma, H. B., Evaporation Heat Transfer in Sintered Porous Media, ASME Journal of Heat Transfer 125 (2003) 644-652.

[16] Hsieh, S.S., Lee, R.Y., Shyu, J.C., and Chen, S.W., Analytical solution of thermal resistance of vapor chamber heat sink with and without pillar, Energy Convers. Manage. 48 (2007) 2708-2717.

[17] Hsieh, S.S., Lee, R.Y., Shyu, J.C., and Chen, S.W., Thermal performance of flat vapor chamber heat spreader, Energy Convers. Manage. 49 (2008) 1774-1784.

[18] Hung-Yi Li, Ming-Hung Chiang, Chih-I Lee and Wen-Jei Yang "Thermal performance of plate-fin vapor chamber heat sinks", International Communications in Heat and Mass Transfer 37 (2010) 731-738

[19] Iverson, B. D., Davis, T. W., Garimella, S. V., North, M. T., and Kang, S. S., Heat and Mass Transport in Heat Pipe Wick Structures, Journal of Thermophysics and Heat Transfer 21 (2) (2007) 392-404.

[20] Kalahasti, S., and Joshi, Y.K., Performance characterization of a novel flat plate micro heat pipe spreader, IEEE Trans. Compon. Packag. Technol. 25 (2002) 554-560.

[21] Khrustalev, D., and Faghri, A., Fluid Flow Effects in Evaporation from Liquid-Vapor Meniscus, ASME Journal of Heat Transfer 118 (1996) 725-730

[22] Kim, S. J., Seo, J. K. and Do, K. H., Analytical and Experimental Investigation on the Operational Characteristics and the Thermal Optimization of a Miniature Heat Pipe with a Grooved Wick Structure, International Journal of Heat and Mass Transfer 46 (2003) 2051-2063.

[23] Koito, Y., Imura, H., Mochizuki, M., Saito, Y., and Torii, S., Theoretical study on heat transfer characteristics of a vapor chamber, Therm. Sci. Eng. 13 (2005) 23-30.

[24] Koito, Y., Imura, H., Mochizuki, M., Saito, Y., and Torii, S., Numerical analysis and experimental verification on thermal fluid phenomena in a vapor chamber, Appl. herm. Eng. 26 (2006) 1669-1676.

[25] Koito, Y., Imura, H., Mochizuki, M., Saito, Y., and Torii, S., Fundamental experiments and numerical analyses on heat transfer characteristics of a vapor chamber (effect of heat source size), JSME Int. J. Series B 49 (2006) 1233-1240.

[26] Koito, Y., Imura, H., Mochizuki, M., Saito, Y. and Torii, S., Numerical Analysis and Experimental Verification on Thermal Fluid Phenomena in a Vapor Chamber, Applied Thermal Engineering 26 (2006) 1669-1676.

[27] Ma, H. B., and Peterson, G. P., Temperature Variation and Heat Transfer in Triangular Grooves with an Evaporating Film, Journal of Thermophysics and Heat Transfer 11 (1997) 90-97.
[28] Morris, S. J. S., Contact Angles for Evaporating Liquids Predicted and Compared with Existing Experiments, Journal of Fluid Mechanics 432 (2001) 1-30.

[29] Morris, S. J. S. The Evaporating Meniscus in a Channel, Journal of Fluid Mechanics 494 (2003) 297-317.

[30] Mwaba, M. G., Huang, X., and Gu, J., Influence of Wick Characteristics on Heat Pipe Performance, International Journal of Energy Research 30 (2006) 489-499.

[31] Ooijen, V., and Hoogendoorn, C. J., Vapor Flow Calculations in a Flat Heat Pipe, AIAA Journal 17 (1979) 1251-1259.

[32] Potash, M., and Wayner, P. C., Evaporation from a 2Dimensional Extended Meniscus, International Journal of Heat and Mass Transfer, vol. 15(10), pp. 1851- 1863, (1972).

[33] Rice, J., and Faghri, A., Analysis of Screen Wick Heat Pipes, Including Capillary Dry-out Limitations, Journal of Thermophysics and Heat Transfer 21(3) (2007) 475-486.

[34] Sait, H. H., and Ma, H. B., An Experimental Investigation of Thin-film Evaporation, Nanoscale and Microscale Thermophysical Engineering, vol. 13, pp. 218-227, (2009).

[35] Sauciuc, I., Chrysler, G., Mahajan, R., Prasher, R., Spreader in the heat sink base: phase change systems or solid metals, IEEE Trans. Compon. Packag, Technol. 25 (2002) 621-628.

[36] Singh, R., A Akbarzadeh and Mochizuki, M., Effect of Wick Characteristics on the Thermal Performance of the Miniature Loop Heat Pipes, ASME Journal of Heat Transfer 131 (2009) 082601 (1-10).

[37] Tan, B.K., Wong, T.N., and Ooi, K.T., Analytical effective length study of a flat plate heat pipe using point source approach, Appl. Therm. Eng. 25 (2005) 2272-2284.

[38] Tournier, J. M., and El-Genk, M. S., A Heat Pipe Transient Analysis Model, International Journal of Heat and Mass Transfer 37 (1993) 753-762.

[39] Vadakkan, U., Murthy, J. Y., and Garimella, S. V., Transient Analysis of Flat Heat Pipes, Procs. ASME Summer Heat Transfer Conference, July 21-23, Las Vegas, Nevada (2003).

[40] Vadakkan, U., Garimella, S. V., and Murthy, J. Y., Transport in Flat Heat Pipes at High Fluxes from Multiple Discrete Sources, ASME Journal of Heat Transfer 126 (2004) 347354.

[41] Wang, Y., and Vafai, K., An experimental investigation of the thermal performance of an asymmetrical flat plate heat pipe, Int. J. Heat Mass Transfer 43 (2000) 2657-2668.

[42] Wang, H., Murthy, J. Y., and Garimella, S. V., Transport from a Volatile Meniscus inside an Open Microtube, International Journal of Heat and Mass Transfer 51 (2008) 3007-3017.

[43] Weibel, J. A., Garimella, S. V., and North, M. T., Characterization of Evaporation and Boiling from Sintered Powder Wicks fed by Capillary Action, International Journal of Heat and Mass Transfer 53 (19-20) (2010) 4204-4215.

[44] Xiao, B., and Faghri, A., A Three-dimensional Thermal-fluid Analysis of Flat Heat Pipes, International Journal of Heat and Mass Transfer 51 (2008) 3113-3126.

[45] Xu, X., and Carey, V. P., Film Evaporation from a Microgrooved Surface An Approximate Heat Transfer Model and its Comparison with Experimental Data, Journal of Thermo physics and Heat Transfer 4 (1990) 512-520.

[46] Zhu, N., and Vafai, K., Analytical Modeling of the Startup Characteristics of Asymmetrical Flat-plate and Disk-shaped Heat Pipes, International Journal of Heat and Mass Transfer 41(17) (1998) 2619-2637. 